\title{
Experiential Marine Geology and Geophysics Education, White Oak Bayou, University of Houston-Downtown
}

\author{
Barnard A ${ }^{1,4,7 *}$, Coutts $A^{2}$, Mackay E3, Zarate $A^{3}$, Max MD $^{4,5}$, Detiveaux G6, \\ Martz J1, Trufan E1, Singh A1, Snow JE7 , Sager WW7, Wellner JS7, Muñoz R¹ \\ and Estes DB ${ }^{8}$
}

1Department of Natural Sciences, 1 Main Street Room 813-North, University of Houston Downtown, Houston, Texas, 77002, USA

2Seatronics Ltd, Denmore Industrial Estate, Bridge of Don, Aberdeen, AB23 8JW, UK

${ }^{3}$ Seatronics Inc., an Acteon company, 1319 West Sam Houston Pkwy North., Suite 150, Houston, Texas, United States of America ${ }^{4}$ Hydrate Energy International, Kenner, Louisiana, 70065, USA

${ }^{5}$ Department of Geology, University College Dublin, Belfield, Dublin 4, Ireland

${ }^{6}$ Center for Teaching and Learning Excellence, University of Houston Downtown, Houston, Texas, 77002, USA

${ }^{7}$ Department of Earth and Atmospheric Sciences, Science \& Research Building 1, 3507 Cullen Blvd, Rm. 312, Houston, Texas, 772045007, USA

${ }^{8}$ Baytown Police Department, 3200 N. Main Street, Baytown, Texas, USA

*Corresponding author: Alex Barnard, Department of Earth and Atmospheric Sciences, Science \& Research Building 1, University of Houston, Texas, 77204-5007, USA, Tel: 832-705-9223; Email: abarnard2@uh.edu

\section{Abstract}

Advanced marine technology is an essential tool used for delivering answers to science-driven questions in underwater environments. Using state of the art technology outdoors encourages intrinsic motivation and provides major opportunities not possible in a laboratory. The University of Houston-Downtown is uniquely situated on the banks of the Buffalo and White Oak Bayous, in closer proximity to an aquatic environment than many world-class marine institutions. Ordinarily, marine research and education focuses on the nearest ocean, lagoon or accessible sea area. We are able to conduct hands-on marine education in a safe shore-based location that is on campus, allowing more of the total time allocated to this activity to be spent learning and operating the equipment rather than traveling. Preliminary underwater investigations of a region of White Oak Bayou that is easily accessible on the campus waterfront were completed in February of 2016 in order to create interest in exploration of natural, and human-made, structures in the local bayou. A Predator (Seatronics Inc., an Acteon company) remotely operated vehicle (ROV) mounted with high-resolution Teledyne BlueView Technologies M900-130 $900 \mathrm{kHz}$ 2D multibeam sonar, and optical-video systems was used as a survey vehicle. Where visibility was too low to use optical imaging details of the bayou floor were recorded by the multibeam system. 


\section{International Journal of Oceanography \& Aquaculture}

The acquired sonar data clearly images fish, large boulders, and several objects that could be hazardous to even shallowdraft boats and recreational water users. Moving the ROV closer to the submerged features allowed visual inspection and analysis of the video images. The students flying the ROV demonstrated our ability to map the bayou floor, evaluate its ecosystem, detect potential hazards, and identify features of interest. Our methodology, where advanced technologies are sourced from industry partners, provides a practical approach that enables high impact educational experiences for students without necessitating the development of long-term programs, thereby leveraging both valuable research funds and outreach opportunities. A central theme of this work is research experiences for students, who would learn workflows, the scale of operations, and challenges involved in exploratory research.

Keywords: Marine technology; underwater equipment; STEM; Training

\section{Introduction}

Geoscience education often lags frontline research; to overcome this challenge we conducted a survey that used advanced marine technology launched from our oncampus dock. The outdoor environment provides opportunities for discussions in an informal and familiar environment that lends itself to the use of a common language and enables students to interact within the group to construct a more holistic understanding of research that would otherwise be inaccessible $[1,2]$. Furthermore, research-based instructional strategies are widely applicable and are part of successful geosciences workforce recruitment [3].

Our novel approach is part of a university-wide initiative to implement high-impact educational practices in student education [e.g., 4] that is being spearheaded by the Center for Teaching and Learning Excellence and Scholars Academy at the University of Houston Downtown (UHD). Implementation of High Impact Practices (HIPS) involves creation of active systematic techniques that enable student engagement and successful learning [4]. Our work addresses four main HIPS practices, these are: 1) experiences for students, 2) research, 3) common intellectual experiences, and 4) collaborative assignments. Inclusion of experiential learning, where students learn from direct experience, in the existing curriculum is a fundamental goal $[5,6]$.

The potential of study areas close to university campuses that could be used for teaching is often overlooked. Ordinarily, when setting a marine teaching or research project, first thoughts for a suitable location may go to the nearest ocean, lagoon, or accessible sea area. The unique location of UHD means that we are able to conduct hands-on teaching in an aquatic environment on campus. From the dockside offshore work can be taught in a shorebased environment thereby maximizing the focus on the training. As time is arguably the most precious commodity, this allows more of the total time allocated to this activity to be spent learning and operating the equipment rather than traveling. By working on campus we can also mitigate risk for the participants and also liability for the university.

Training of industry field crews that undertake survey work was traditionally carried out in house by companies, but recently expectations of graduates require higher levels of training and ready-to-go skills. The reduced capacity for training in industry and increased demand for skilled personnel have resulted in several industryrelevant training courses being offered through professional organizations and at university field camps [7]. Our approach, at the undergraduate level, is to provide hands-on experience with advanced marine technology that encourages intrinsic motivation without requiring a university to have a separate field program. This collaborative and experiential learning approach promotes student performance and critical thinking and is part of creating a meaningful way to increase student engagement in education [8-10].

\section{Study Area}

The UHD dockside location includes waterfront campus along the confluence of Buffalo and White Oak bayous, providing an exceptional natural laboratory for aquatic science. The word 'bayou' is derived from the native Choctaw word "bayuk", which means creek and the bayou in this region has a rich history but this reach has been overlooked as a potential outdoor classroom or research space due to its present form as a major channel in the City's drainage system.

In 1837, the first steamboat to visit Houston, Laura, took 3 days to make the trip from Harrisburg and could not find the City of Houston because of overhanging trees 


\section{International Journal of Oceanography \& Aquaculture}

and log jams on the bayou. On June 10, 1841, the Port of Houston was established at the confluence of White Oak and Buffalo Bayou. The port moved 6 miles downstream when the Houston Ship Channel opened in 1914. It is likely that since the Port of Houston moved location this reach of the bayou that was once suitable for marine trade, has not been dredged.

The reach of White Oak Bayou adjacent to UHD is $20-$ 30 meters wide and prior to the survey no water depth information was available. The bayou generally has a high suspended, and dissolved sediment concentration, and algae growth, that reduce visibility in its waters and obscure the bayou floor. In addition, because of the brown color of the suspended sediments the bayou is often thought of as being dirty. In reality, the bayou contains and sustains a functional ecosystem that is effectively invisible to visual inspection. Because of the buildup of the city, this once natural channel is infrequently overwhelmed by surface runoff and storm discharges that increase point source pollution, and at these times the water quality in the bayou may be lower than usual [1113]. Built on ideas proposed by Comey, Houston's recently invigorated Bayou Greenway Initiative has established a $\$ 480$ million project to create bayou parks that connect the 10 largest bayous in Houston [14]. This is a major environmental project aimed at benefiting the city and its residents [15]. Mayor Annise Parker, and Rich and Nancy Kinder (Kinder Foundation) opened Buffalo Bayou Park on October 3rd, 2015, a park that reaches from UHD to the west of downtown, with further expansion into East Houston planned.
Studying the bayous creates a link between the classroom and outdoor activities that could form part of student's everyday lives. The application of marine technology serves a valuable societal, as well as training, purpose. Providing a connection to work that is locally important generates motivation and nurtures students who may come from afar.

\section{Materials and Implementation}

Based on our rationale for field experience, and after gathering students interested in the subject matter, we approached the university to implement safe working operations. Following several safety meetings, we organized an event at which students would use a Remotely Operated Vehicle (ROV) to investigate what lies beneath the murky bayou waters. To prepare for the event we conducted a visual inspection of several sites around UHD to determine the best location for student involvement in bayou research. Several locations were possible, but the dockside adjacent to the Willow Street Pump Station was chosen because of its ease of access for students, equipment, and power. We operated a small portable electricity generator, required to power the ROV and instruments, in a nearby car park (Figure 1). Prior to launching the ROV we did not have measurements of the bayou depth, but from manual soundings we estimated it to be in the order of one to two meters deep. Similarly, we were aware that there were likely several hazards on the bayou floor. A first pass of the ROV over the survey area at the surface was decided upon so as to avoid and identify any potential hazards at depth.

$$
\text { Houston planned. }
$$

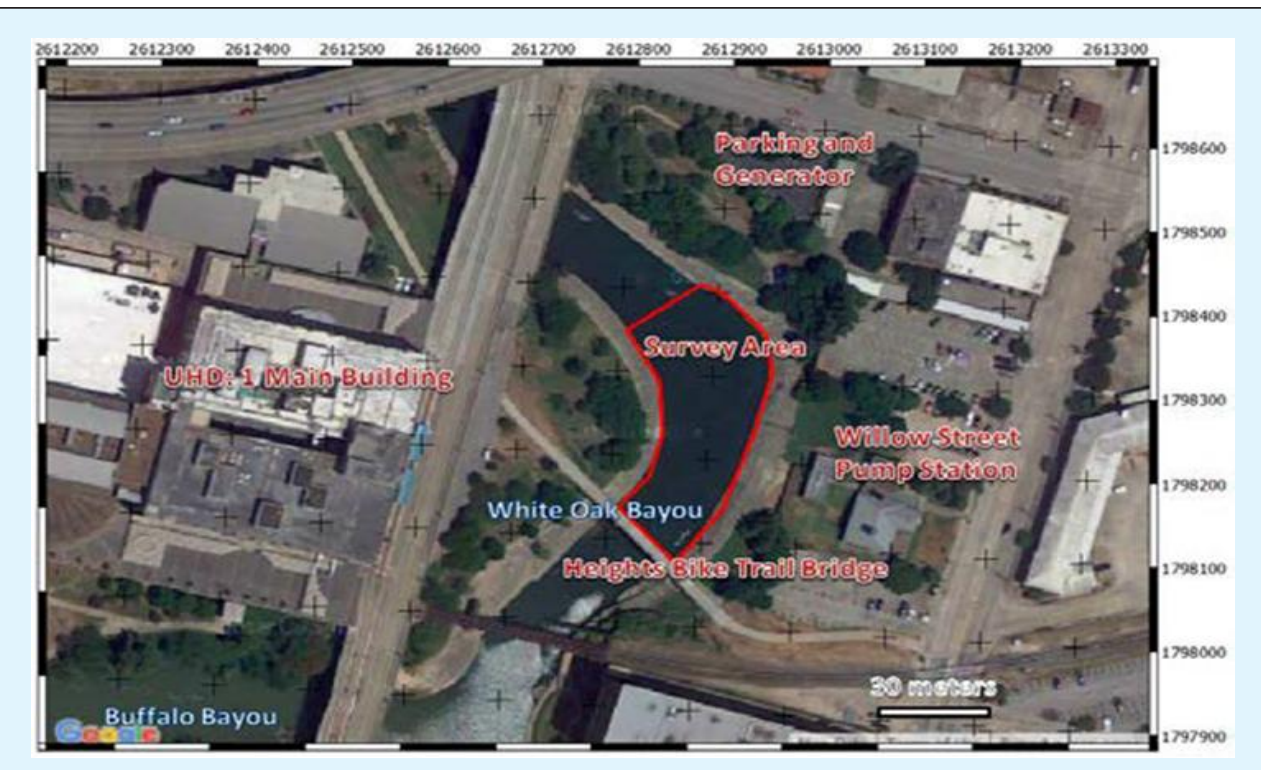

Figure 1: Location map of the field study area on White Oak Bayou on the University of Houston-Downtown campus. The reach of bayou surveyed is outlined in red and the places used as part of the training are labeled. Image created using open source QGIS (www.qgis.org), NAD83 TX (N) ft. (EPSG: 3668), scale in meters added for reference purposes. 


\section{International Journal of Oceanography \& Aquaculture}

\section{Equipment}

Equipment is expensive for universities to obtain, maintain and calibrate as it may be used infrequently and is therefore prone to both calibration errors and damage. Equipment is often better sourced from rental companies or industry partners who in turn gain exposure though both the universities students and university. Our methodology, where materials are sourced from industry partners instead of being purchased and left on a shelf for most of the year, provides a widely applicable and practical approach that would allow others in the geosciences education community without long-term programs to provide high impact educational experiences for students, and leverage valuable research funds. Access to marine technology is a limiting factor for most developing marine programs so it is research partnerships and collaboration that stimulate growth [16]. In this case, we collaborated with Seatronics Inc., an Acteon company, to conduct an ROV demonstration on the UHD campus dockside. We used a Predator II (Seatronics Inc., an Acteon company, Houston, Texas) 300 meter rated inspection class ROV that has a maximum speed of $\sim 5-6 \mathrm{~km} / \mathrm{hr}$. The weight of the ROV is $\sim 80 \mathrm{~kg}$ in air. Impellors on the ROV use brushless electric motors from a topside power generator sent to the ROV through the tether. The ROV was mounted with a high resolution wide angle color video camera and Teledyne BlueView Technologies M900-130 $900 \mathrm{kHz}$ 2D multibeam sonar. The ROV also houses several other sensors such as pitch and roll, and a pressure sensor used to determine water depth.

\section{Activities}

The event ran from 10:00 - 16:00 in fair weather and drew a crowd; faculty from UHD, University of Houston, University of Houston Clear Lake and $\sim 36$ students attended. About $\sim 15$ students were present at any one time. The invited guest speaker, Louis F. Aulbach from Texas Historical Commission and the Houston Archaeological Society provided a detailed history of the bayou [17]. Two undergraduate students actively participated in helping set up the "topside" equipment, tethering the ROV, and checking the equipment which took about 2 hours, e.g., Figure 2. This was followed by two hours of hands-on experience with the ROV in the water during which time $\sim 15$ students took turns flying the ROV (Figure 3 ). Students found they could easily move and maintain position of the ROV even in areas of the channel with relatively strong currents. The ROV technology and its sensors were then presented to students by the visiting industry experts and its capabilities were demonstrated (30 minutes), followed by presentations on the archaeology and history of the bayou, and an introduction to marine geology and geophysics. We allocated as much time as possible for students to get hands-on experience with the ROV, with a professional pilot standing by, throughout the day to focus on student experience and engagement.

\section{Exploration}

Students were introduced to the ROV, its controls, and instrumentation on the dockside. Each of the $\sim 36$ students had opportunities to control the vehicle as we explored the bayou. The first exploratory run was conducted from the surface to gauge the depth and bottom conditions. After determining we could safely conduct a more detailed survey, the students flew the ROV in parallel flights across the bayou to identify targets for more detailed inspection. Two main geophysical sensors were employed: imaging sonar and optical imaging. Combined, these systems provided information on a broad swath of the bayou floor and its banks.

We were able to acoustically image objects $\sim 10$ meters in front of the ROV. The sonar could return images of regions underwater where the suspended sediment would not permit optical imaging. Moreover, the video systems provided ease of recognition for targets once the vehicle was maneuvered into a position close enough ( $\sim 1$ meter). As well as controlling the ROV, students were able to manipulate the sensors to improve the images viewed and recorded.

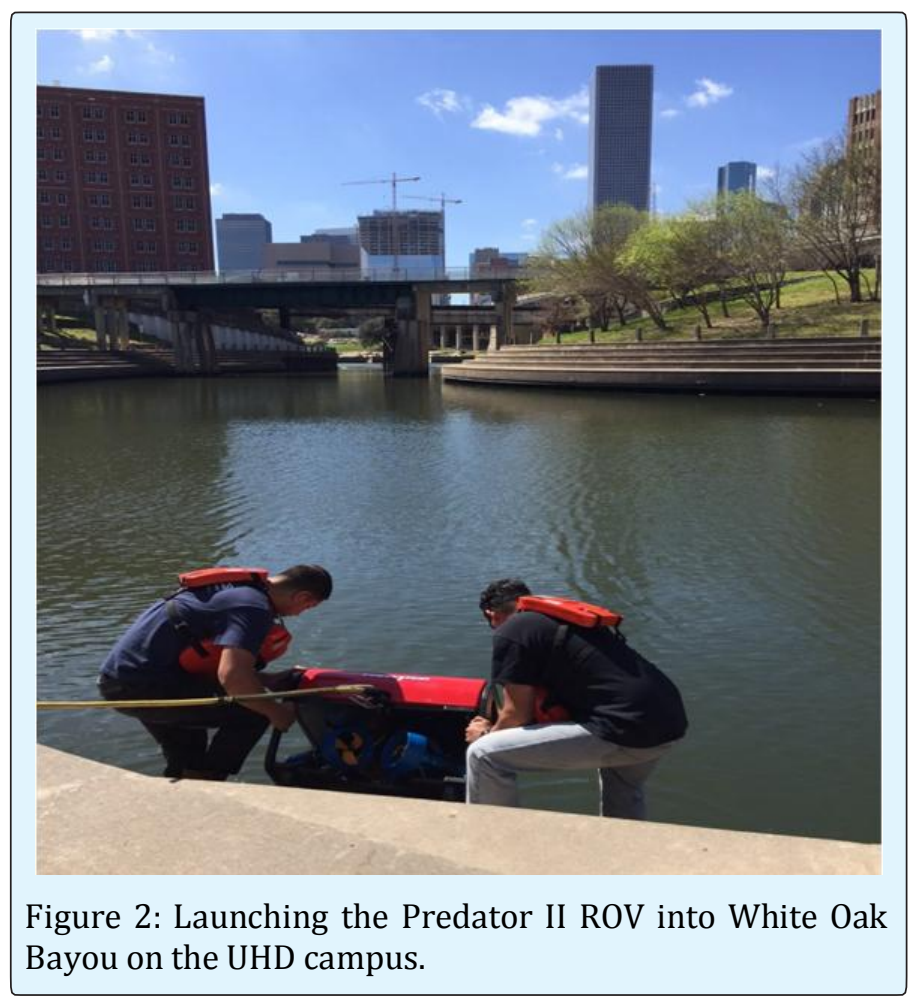




\section{Interpretation of Bayou Exploration Data}

Exploration of the bayou identified several features that were visible above the water surface and also several interesting features that were not known prior to the survey (e.g., Figure 4C, D \& E). There was a great amount of collaborative sharing of ideas and team problem solving to maneuver the ROV into positions to answer student questions about features. We found that the depth of the bayou varied from $\sim 0.5$ meters in the northern reaches to 2 meters beneath the Heights Bike Trail Bridge in the south. To student delight, several fish $(\sim 10$ inches $)$ were observed in the deeper parts of the bayou. We were also able to identify several carts, cables and large boulders in the stream channel that could be potential hazards for recreational water users and small boats.

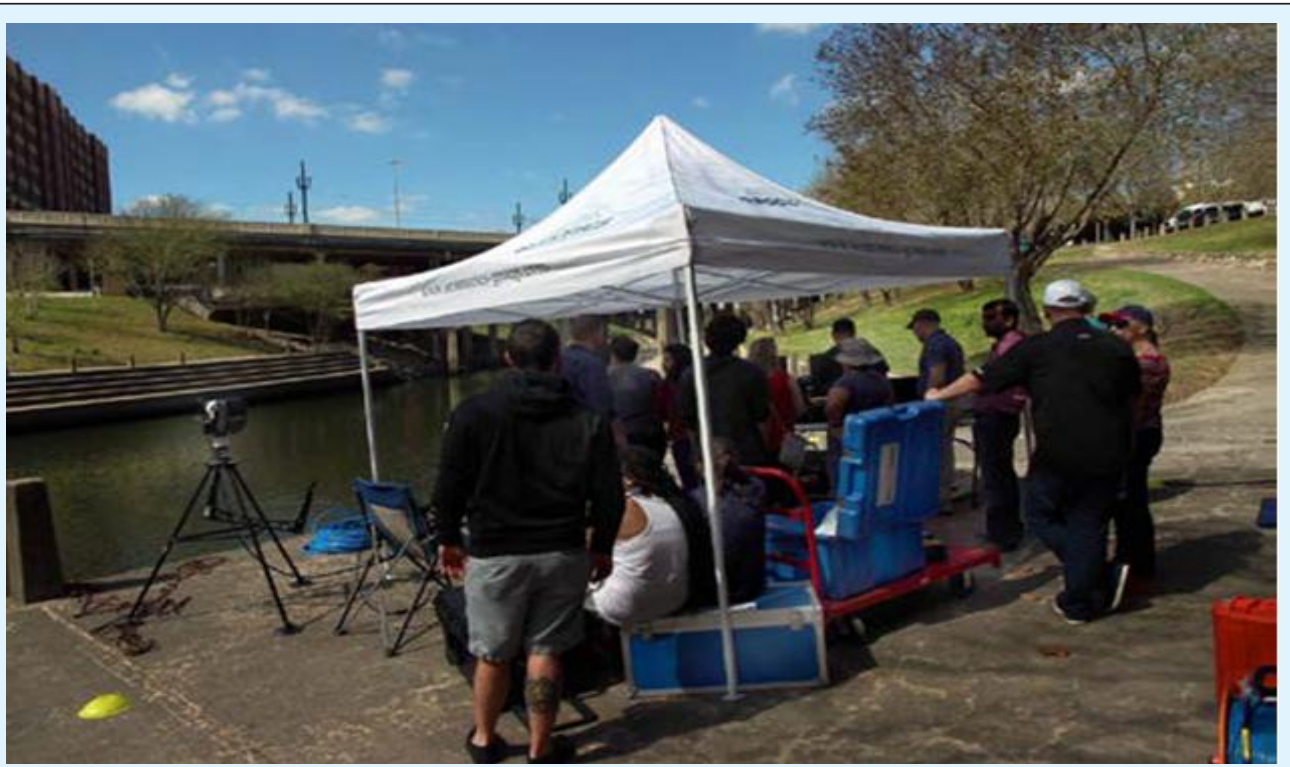

Figure 3: Students enjoying working dockside on the ROV topsides.

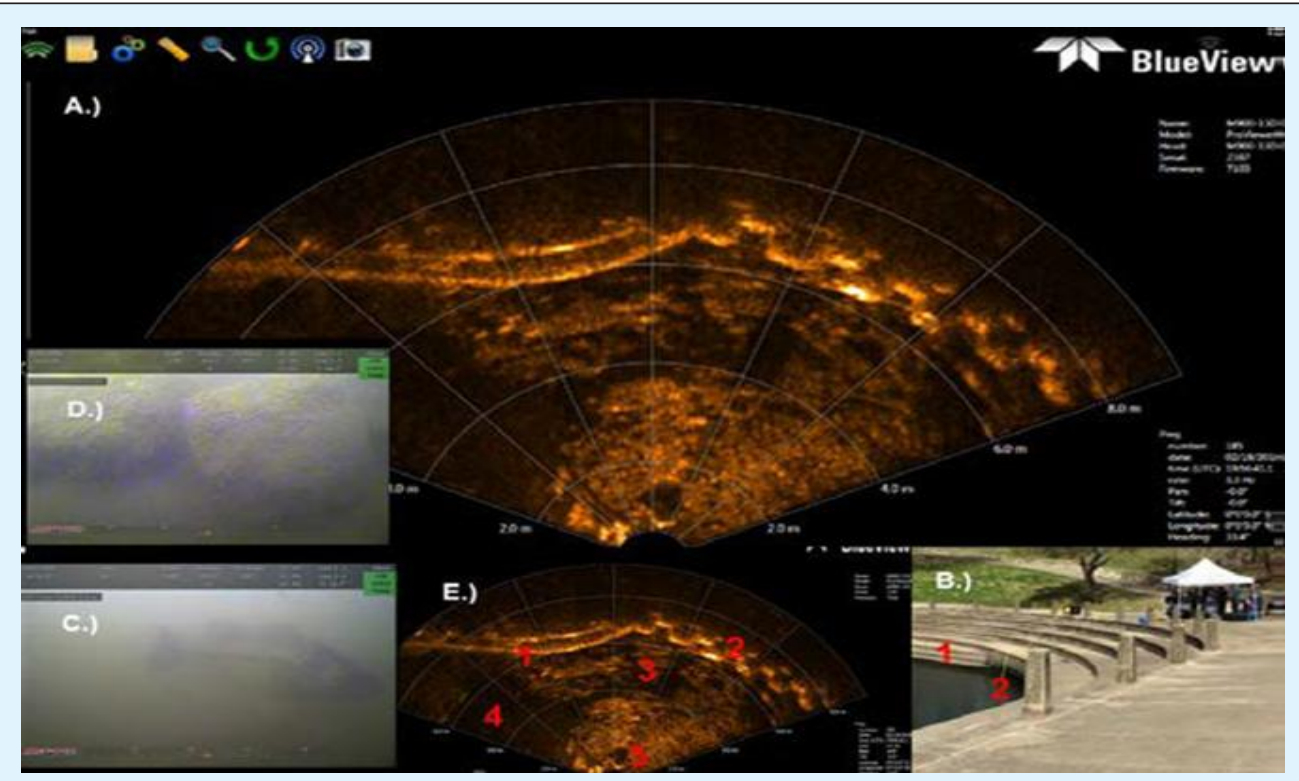

Figure 4: A) View from multi beam imaging sonar of the bayou floor. In the sonar imagery bright regions represent strong acoustic reflections from either hard materials or objects angled towards the receiver. B) Photograph of the survey region showing: 1) concrete steps, and 2) corrugated metal. C) Largemouth bass (fish). D) Boulders in the stream channel. E) Sonar image with interpretation of significant features: 1) concrete steps, 2) corrugated metal, 3) debris/tires, 4) muddy bayou floor, and 5) fish. 


\section{International Journal of Oceanography \& Aquaculture}

While the ROV was in the bayou waters, the sensors were continuously recording data. This data was synchronously presented on computer monitors and stored on a hard drive. Because we did not set up a location recording GPS base station, the acoustic measurements taken in the bayou were relatively positioned using known locations.

Back in the laboratory, students played back the acoustic imagery using Teledyne BlueView Pro Viewer v4.3 (Table 1). By matching the time stamps in both datasets we were able to match both the sonar and optical image data. This taught students how to integrate data and the importance of making more robust interpretations with multiple data sets. In some cases, the optical imagery couldn't be used for target recognition due to the low light penetration in the bayou water.

\begin{tabular}{|c|c|c|c|c|}
\hline Dataset & $\begin{array}{c}\text { Files } \\
\text { Acquired }\end{array}$ & File Size & File & Software \\
\cline { 3 - 3 } type & (mb per file) & Used \\
\hline $\begin{array}{c}\text { Multi } \\
\text { beam }\end{array}$ & 38 & $\sim 200$ & .son & $\begin{array}{c}\text { BlueView } \\
\text { Pro Viewer } \\
\text { v4.3 }\end{array}$ \\
\hline Video & 1 & $\sim 500$ & .avi & $\begin{array}{c}\text { Windows } \\
\text { Movie }\end{array}$ \\
\hline
\end{tabular}

Table 1: Information about the files acquired during acquisition and software used for data processing.

\section{Implications}

The data acquired during this activity has been used in courses taught at UHD that teach the fundamentals of oceanography and geosciences, and were used in a student poster presentation at student research day [18]. Once students become familiar and interested in marine activities there are opportunities for them to get involved with broader research projects remotely as well as the more traditional industry (internship) and academic (research) routes [19]. Several global oceanographic institutions now broadcast their work through the internet (e.g., NOAA, NAUTILUS LIVE, IODP, NOCS), allowing students direct access to frontline research.

\section{Summary}

As part of this exercise students were able to get handson experience with advanced marine technologies. The day was wrapped up with a debriefing ( $\sim 1$ hour) on the equipment used, the past and present significance of the bayou, and a discussion on data acquisition and interpretation. A student also presented this work at UHD student research day. Because this research was conducted outdoors, it allowed students to engage with marine technology equipment and learn more about the natural environment in a familiar setting that stimulated more questions and discussion than would have been possible in a traditional classroom environment. We identified fish and several objects in the bayou that indicated there is potential in the future for more detailed exploration.

\section{Acknowledgments}

Special thanks to Seatronics Inc., an Acteon company, for supplying the Predator II ROV. This work is supported by the Center for Teaching and Learning Excellence (CTLE) Competitive High Impact Practices (HIPS) award to $A B$ (2016). We are grateful to Louis F. Aulbach for sharing his expertise on Houston's bayous with us and would also like to thank Buffalo Bayou Partnership (BBP) and the Professional Tour Guide Association of Houston (PTGAH) for up-to-date historical information about the bayou.

\section{References}

1. Kortz KM, Caulkins AR (2015) Introductory geology: Is there a common language? GSA Today 25(10): 4243.

2. Marcum-Dietrich N, Marquez L, Gill SE, Medved C (2011) No teacher left inside: Preparing a new generation of teachers. J Geosci Educ 59(1): 1-4.

3. La Due ND, Pacheco HA (2013) Critical experiences for field geologists: emergent themes in interest development. J Geosci Educ 61: 428-436.

4. Kuh GD (2008) Excerpt from High-Impact Educational Practices: What They Are, Who Has Access to Them, and Why They Matter. Assoc of Am Colleges and Univ, Washington, DC.

5. John Dewey (1938) Experience and Education. New York, Macmillan.

6. Kolb DA, Fry RE (1974) Toward an applied theory of experiential learning: MIT Alfred P. Sloan School of Management, Cambridge, Mass.

7. Stewart RR, Khan S, Hall S, Liner C, Wong J (2010) Geophysics field education: Better learning by doing. The Leading Edge 29(5): 546-550.

8. Nnodim JO (1997) A controlled trial of peer-teaching in practical gross anatomy. Clin Anat 10(2): 112-117. 


\section{International Journal of Oceanography \& Aquaculture}

9. Breunig M (2005) Turning experiential education and critical pedagogy theory into praxis. Journal of Experiential Education 28(2): 106-122.

10. Yacobucci MM (2013) Integrating Critical Thinking about Values into an Introductory Geoscience Course. J Geosci Educ 61: 351-363.

11. Cantrell K, Leija LD, Henderson JD, Vasquez J, Johnson $\mathrm{K}$, et al. (2007) Dissolved metal abundances in bayou waters from Harris County, Texas; a possible monitor of subsidence in the Houston-Galveston area. Geological Society of America Abstracts with Programs 39(3): 58.

12. Schmertz M (2003) Houston focuses on the restoration and development of the Buffalo Bayou, a historic waterway. Architectural Record 191(8): 55.

13. Petersen TM, Suarez MP, Rifai HS, Jensen P, Su YC, et al. (2006) Status and trends of fecal indicator bacteria in two urban watersheds. Water Environ Res 78(12): 2340-2355.

14. Comey AC (1913) Houston: Tentative Plans for Its Development: Report to the Houston Park Commission. Rice University, Press of Geo H Ellis Company.
15. Crompton JL (2012) Estimates of the Economic Benefits accruing from an expansion of Houstons Bayou Greenway Network. Journal of Park and Recreation Administration 30.

16. Gilligan MR, Verity PG, Cook CB, Cook SB, Booth MG (2007) Building a diverse and innovative ocean workforce through collaboration and partnerships that integrate research and education: HBCUs and Marine Laboratories. J Geosci Educ 55(6): 531-540.

17. Aulbach LF (2011) Buffalo Bayou: An echo of Houston's wilderness beginnings: Create Space Independent Publishing Platform.

18. Muñoz R, Barnard A, Coutts A, Mackay E, Max MD, et al. (2015) Remotely Operated Vehicle Based Exploration of White Oak Bayou, Main Street Campus, University of Houston-Downtown, in University of Houston-Downtown Student Research Day, Houston, Texas, USA.

19. Pallant A, McIntyre C, Stephens AL (2016) Transforming undergraduate research opportunities using telepresence. J Geosci Educ 64(2): 138-146. 